\title{
Effect of software version and parameter settings on the marginal and internal adaptation of crowns fabricated with the CAD/CAM system
}

\author{
Ji Suk SHIM', Jin Sook LEE, Jeong Yol LEE², Yeon Jo CHOI', Sang Wan SHIN², Jae Jun RYU \\ 1- Korea University Ansan Hospital, Department of Prosthodontics, Gyeonggi-do, Republic of Korea. \\ 2- Korea University Guro Hospital, Department of Prosthodontics, Seoul, Republic of Korea. \\ 3- Korea University Anam Hospital, Department of Prosthodontics, Seoul, Republic of Korea.
}

Corresponding address: Jae Jun Ryu - Department of Advanced Prosthodontics, Korea University Anam Hospital - 73, Inchon-ro - Seongbuk-gu - Seoul 136-705 - Republic of Korea - Phone: +82-2-920-5423 - Fax: +82-2-866-1499 - e-mail: koprosth@unitel.co.kr

Submitted: March 18, 2015 - Modification: June 16, 2015 - Accepted: July 11, 2015

\section{ABSTRACT}

\begin{abstract}
$\mathrm{O}$ bjective: This study investigated the marginal and internal adaptation of individual dental crowns fabricated using a CAD/CAM system (Sirona's BlueCam), also evaluating the effect of the software version used, and the specific parameter settings in the adaptation of crowns. Material and Methods: Forty digital impressions of a master model previously prepared were acquired using an intraoral scanner and divided into four groups based on the software version and on the spacer settings used. The versions 3.8 and 4.2 of the software were used, and the spacer parameter was set at either $40 \mu \mathrm{m}$ or $80 \mu \mathrm{m}$. The marginal and internal fit of the crowns were measured using the replica technique, which uses a low viscosity silicone material that simulates the thickness of the cement layer. The data were analyzed using a Friedman two-way analysis of variance (ANOVA) and paired t-tests with significance level set at $p<0.05$. Results: The two-way ANOVA analysis showed the software version $(p<0.05)$ and the spacer parameter $(p<0.05)$ significantly affected the crown adaptation. The crowns designed with the version 4.2 of the software showed a better fit than those designed with the version 3.8, particularly in the axial wall and in the inner margin. The spacer parameter was more accurately represented in the version 4.2 of the software than in the version 3.8. In addition, the use of the version 4.2 of the software combined with the spacer parameter set at $80 \mu \mathrm{m}$ showed the least variation. On the other hand, the outer margin was not affected by the variables. Conclusion: Compared to the version 3.8 of the software, the version 4.2 can be recommended for the fabrication of well-fitting crown restorations, and for the appropriate regulation of the spacer parameter.
\end{abstract}

Keywords: Software. Design. Margin.

\section{NTRODUCTI ON}

Digital impression systems using intraoral scanning have been available since the introduction of CEREC 1 (Sirona's BlueCam) as part of the single-sitting dental appointment concept ${ }^{18}$. These systems offer remarkable benefits compared with conventional impression methods, including easier data storage, smaller storage requirements, more time-efficient treatment procedures, and an increase in patient comfort ${ }^{9}$. However, restorations fabricated with the first digital impression systems available showed relatively poor marginal adaptation compared to the ones made with conventional impression methods ${ }^{13}$; therefore, some authors expressed concerns on the longevity of the restorations, since adequate marginal adaptation is a decisive factor for clinical longevity ${ }^{10}$. On the other hand, technical advances have significantly improved the adaptation of restorations fabricated with digital impression systems; a recent study demonstrated that a complete crown fabricated using intraoral scanning resulted in a better marginal fit than crowns created with conventional techniques ${ }^{17}$.

The process of fabricating restorations using 
digital impressions and "computer-aided-design/ computer-aided-manufacturing" (CAD/CAM) technology comprises the following steps: data acquisition, data processing, and manufacturing. These steps are equally important for the fabrication of well-fitting restorations, and errors in any of these steps may result in distortions of the restorations ${ }^{19}$. Therefore, the scanning procedure, the specific software, and the milling machine used have all been suggested as factors that could have a detrimental effect on the fit of restorations fabricated with the CAD/CAM technology ${ }^{2,21}$. As a consequence, a number of studies have been performed to compare marginal and internal adaptation of restorations scanned with different intraoral scanners or fabricated made with different milling machines. However, to perform accurate comparisons it is also essential to take into account the software version used with each CAD/CAM system and the specific parameter settings (i.e. spacer settings) selected. Despite the importance of these factors, few studies have assessed their effect on marginal and internal adaptation of crown restorations. Therefore, the purpose of this study was to evaluate marginal and internal adaptation of restorations fabricated with different versions of the CAD/CAM software and the effect of different parameter settings.

\section{MATERI AL AND METHODS}

\section{Fabrication of the reference model}

An acrylic model of the maxillary left second molar was prepared to receive a single ceramic crown restoration (Nissin Dental Model, Nissin Dental Prod. Inc., Kyoto, Kyoto, Japan). The preparation featured a 1 -mm-deep chamfer finish line with a total convergence angle of 12 degrees. To verify a standardized tooth reduction, an initial impression was taken with a vinyl polysiloxane material (Aquasil Soft Putty, Dentsply DeTrey GmbH, Konstanz, Baden-Württemberg, Germany) before preparation. This impression was sectioned vertically (at a width of $2 \mathrm{~mm}$ ), and set in the place of the prepared model. The depth needed for tooth preparation was estimated by comparing the impression body and the prepared model. For repeated measurements, a titanium replica of the acrylic model was made using a customized CAD/ CAM system (Myplant, Addtech Co., Seoul, Seoul, Korea).

\section{Acquisition of digital impressions}

A thin uniform layer of an antireflection powder (CEREC Optispray, Sirona Dental Systems GmbH, Bensheim, Hesse, Germany) was sprayed on the reference model. Digital impressions were taken using a CEREC AC with Bluecam (Sirona's BlueCam,
Sirona Dental Systems GmbH, Bensheim, Hesse, Germany) system according to the scanning protocol of Ender and Mehl $^{9}$ (2013), including occlusal views with scans at an angle of 30 degree from the buccal and lingual surfaces ${ }^{5}$. One single dentist trained in taking digital impressions acquired 40 digital impressions of the reference model.

\section{Data processing and fabrication of single crowns}

The 40 digital impressions acquired were first divided into two groups ( $n=20$ each), depending on the software version that was used in the processing (i.e., CEREC version 3.8 or version 4.2). Each group was further divided into two subgroups ( $n=10$ each), depending on the spacer parameter settings (i.e., 40 or $80 \mu \mathrm{m}$ ) (Table 1 ). The acquired datasets were transmitted to a milling unit (CEREC MCXL, Sirona Dental Systems $\mathrm{GmbH}$, Bensheim, Hesse, Germany), and crowns were fabricated using Lava ${ }^{\mathrm{TM}}$ Ultimate Restorative milling blocks (3M ESPE, St. Paul, Minnesota, USA).

\section{Evaluation of crow $\mathrm{n}$ adaptation}

The replica technique previously described by Molin and Karlsson ${ }^{15}$ (1993), and validated by Rahme, et al. ${ }^{22}$ (2008) and Laurent, et al. ${ }^{12}$ (2008), was used to evaluate the adaptation of crowns. The crowns were filled with a low viscosity silicone material (Fit Checker, GC Dental, Tokyo, Tokyo, Japan), and placed in the titanium reference model using a Shimadzu universal tester (AG-10KNX, Shimadzu Co, Tokyo, Tokyo, Japan) with a $20 \mathrm{~N}$ load. After 5 minutes, the silicone material attached to the internal surface of the crowns was removed and then stabilized with the impression material of higher viscosity (Examixfine regular type, GC Dental, Tokyo, Tokyo, Japan).

All replicas were cut along the abutment axis both in the buccolingual and in the mesiodistal direction, using a razor blade, yielding four fragments per crown. For each cross section, four points were measured, thus 16 thickness points of the titanium replica were measured (Figure 1 ). The points from " 1 " to " 8 " were included in the buccolingual direction section, and the points from "a" to " $h$ " were included in the mesiodistal direction section. The measuring points were divided into 4

\begin{tabular}{|l|c|c|}
\hline & $\begin{array}{c}\text { Software } \\
\text { version }\end{array}$ & $\begin{array}{c}\text { Spacer } \\
\text { parameter }\end{array}$ \\
\hline Group 1 $(n=10)$ & Cerec SW 3.8 & $40 \mu \mathrm{m}$ \\
\hline Group 2 $(n=10)$ & Cerec SW 3.8 & $80 \mu \mathrm{m}$ \\
\hline Group 3 $(n=10)$ & Cerec SW 4.2 & $40 \mu \mathrm{m}$ \\
\hline Group 4 $(n=10)$ & Cerec SW 4.2 & $80 \mu \mathrm{m}$ \\
\hline
\end{tabular}

Figure 1- Groups defined for the study 
categories considering the location of tooth: margin $(1,8, a, h)$, lower axial wall $(2,7, b, g)$, upper axial wall $(3,6, c, f)$, and occlusal surface $(4,5, d, e)$.

All analyses were performed using a double-blind protocol. Replica film thickness was measured with a video measuring system (Optical video measuring system, Seven Ocean Optical Technology, Donnguan, Guangdong, China) at a $10 \mathrm{X}$ magnification with external light source.

\section{Statistical analysis}

The mean and the standard deviation of the fit accuracy were calculated for each group. The influence of independent variables, including the ones from the software and from the spacer parameters, were analyzed using a Friedman twoway analysis of variance (ANOVA) $(p=.05)$. A post hoc analysis was performed using the Friedman multiple comparisons.

The groups within each category (margin, lower axial wall, upper axial wall, occlusal surface) were merged, and the mean and the standard deviation of each category were calculated. The comparisons between groups within each category were conducted using paired t-tests $(p<05)$. All statistical analyses were carried out with MedCalc version 12.5.0 (MedCalc Software, Ostend, Vlaanderen, Belgium).

\section{RESULTS}

The accuracy of the fit at each measuring point for each experimental group is summarized in Figures 2 to 6 . Statistical significances between groups were demonstrated in Figures 7 and 8. The results drawn from the average values of the same categorized measuring points are shown in Figure 9.
The two-way ANOVA analysis showed the software version and the spacer parameter significantly affected the fit of crowns $(p<.05)$ (Table 1$)$.

The accuracy of the fit of all measuring points on the margin $(1,8, a, h)$ showed no statistical significant difference between groups, and the average values of measuring points categorized as the margin also showed no significant difference $(p>.05)$. On the lower and on upper axial wall, some specific measuring points (i.e., points 2 and $\mathrm{g}$ of the lower axial wall; points 3 and $\mathrm{f}$ of the upper axial wall) showed a significantly larger gap when data were processed using the version 3.8 of the software compared with the version 4.2 of the software, regardless of the spacer settings used. Measuring points 6 (upper axial wall) and 7 (lower axial wall) showed a significantly larger gap using the version 3.8 of the software compared with the 4.2 of the software when the spacer parameter was set at $40 \mu \mathrm{m}(p<.05)$. The comparison of the average values of the measuring points categorized as lower axial wall and upper axial wall showed a significantly larger gap using the version 3.8 of the software, regardless of the spacer parameter used $(p<.05)$. In the occlusal surface, measuring points $\mathrm{d}$ and e showed a significantly larger gap when the data were processed using the version 3.8 of the software compared with the version 4.2 of the software, regardless of the spacer parameter used; while measuring point 4 showed the same result only when the spacer parameter was set at $80 \mu \mathrm{m}$ $(p<.05)$. The comparison of the average values of the occlusal surface showed the group processed with the version 3.8 of the software had a larger gap compared with the group processed with the version 4.2 of the software only when the spacer parameter was set at $40 \mu \mathrm{m}(\mathrm{p}<.05)$.
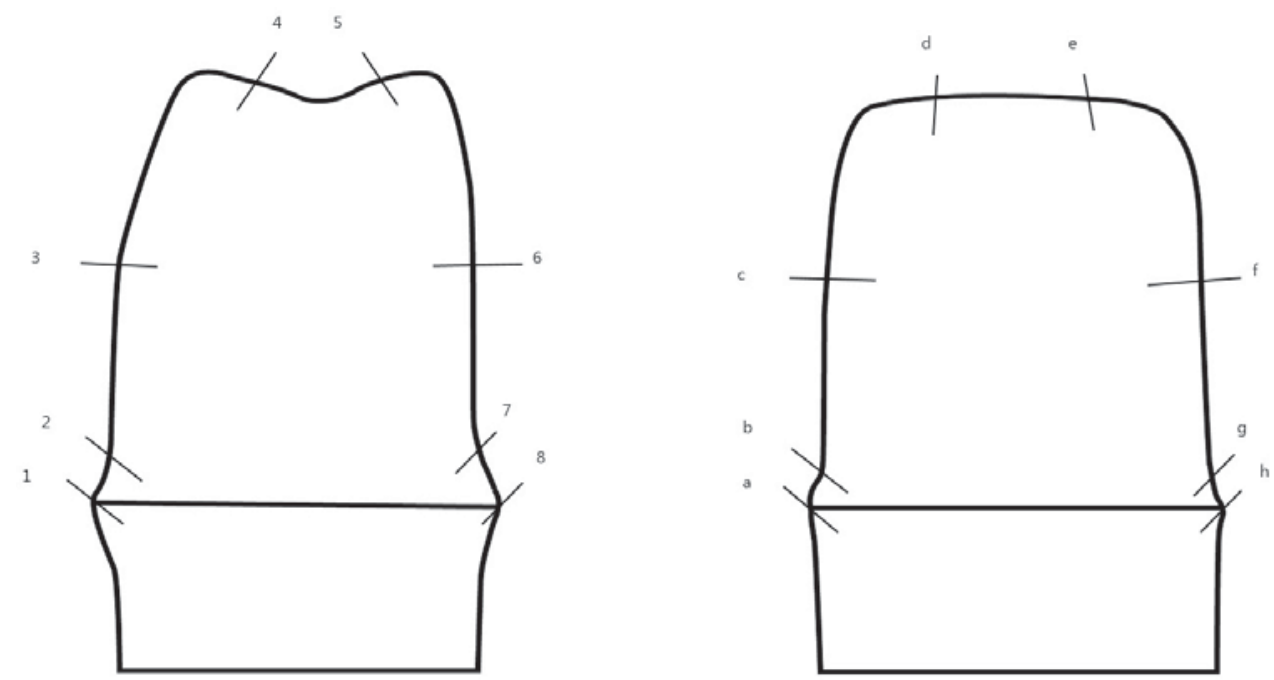

Figure 2- Measuring points for evaluation of crown fit. The points 1 to 8 are positioned on the buccolingually sectioned surface, and a to $\mathrm{h}$ are on the mesiodistally sectioned surface. Points of $1,8, \mathrm{a}, \mathrm{h}$ are positioned on the margin, 2, 7, b, $\mathrm{g}$ are on the lower axial wall, 3, 6, c, f are on the upper axial wall, and 4, 5, d, e are on the occlusal surface 


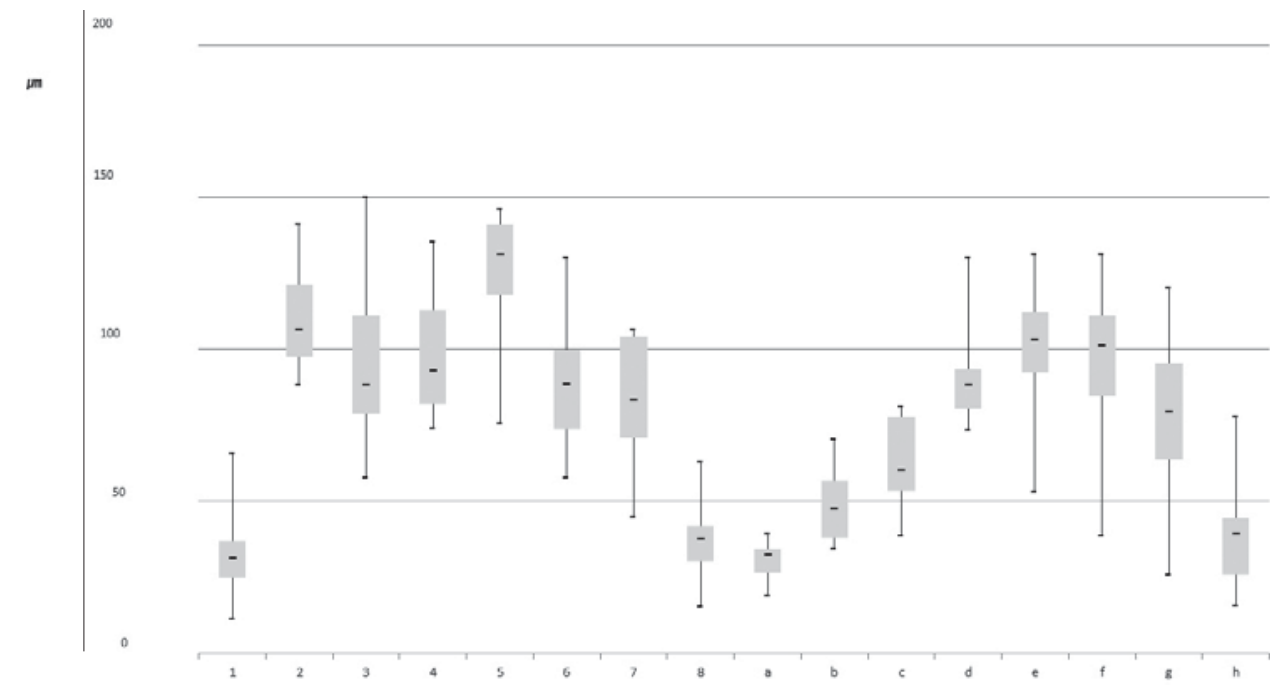

Figure 3- Accuracy of fit of each measuring point in group 1 (CEREC SW 3.8, $40 \mu \mathrm{m}$ ). Uppermost point and lowermost point indicate the highest and lowest values of results. The top of box and bottom of box indicate the $75 \%$ and $25 \%$ values of results. The midline in the box means the average of the results

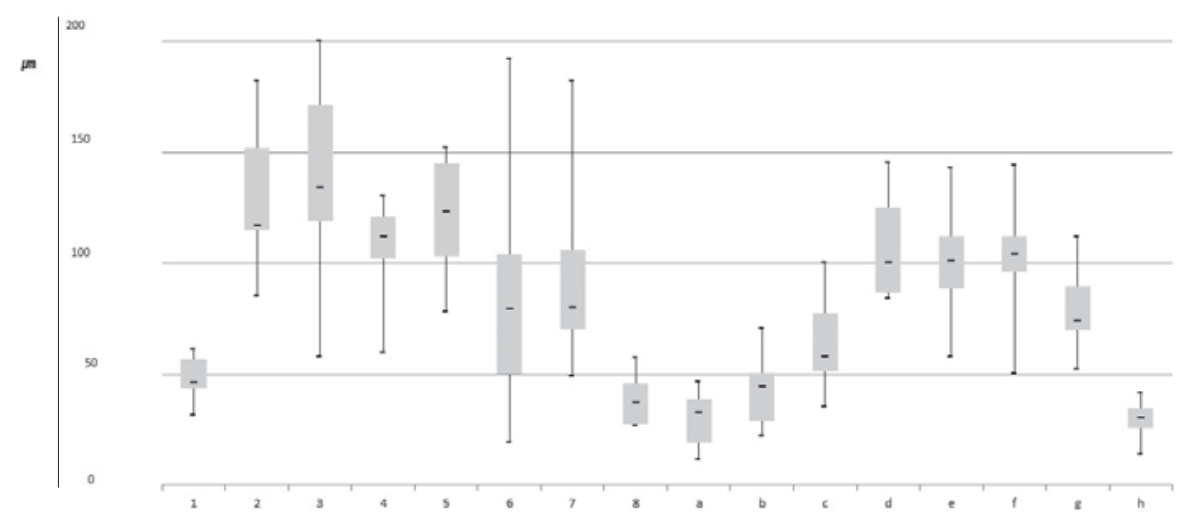

Figure 4- Accuracy of fit of each measuring point in group 2 (CEREC SW 3.8, $80 \mu \mathrm{m}$ ). Uppermost point and lowermost point indicate the highest and lowest values of results. The top of box and bottom of box indicate the $75 \%$ and $25 \%$ values of results. The midline in the box means the average of the results

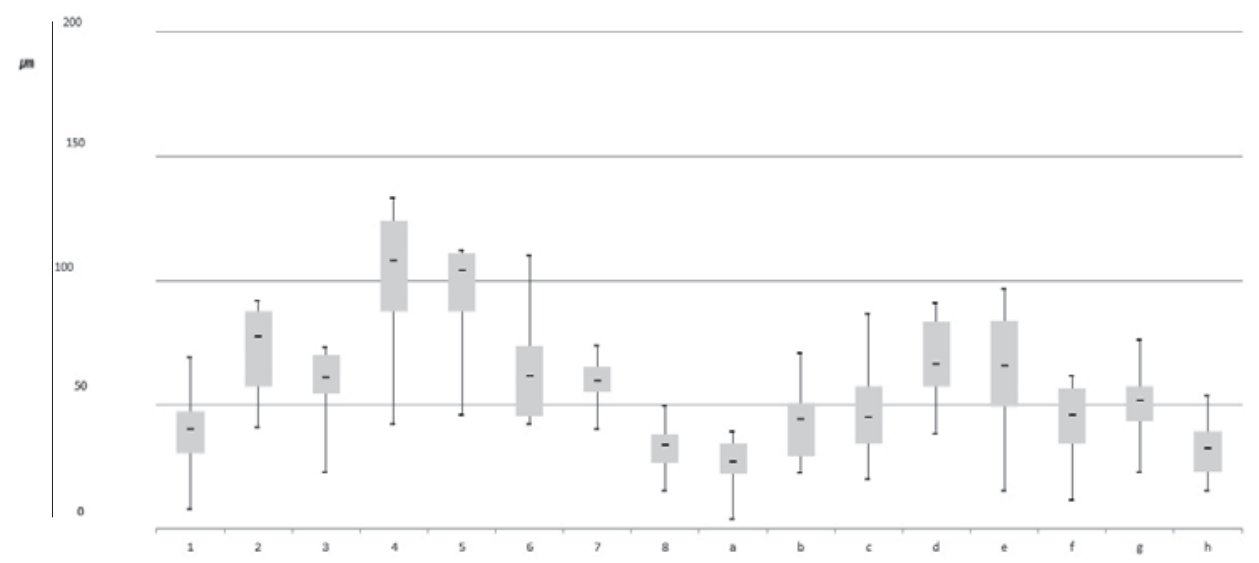

Figure 5- Accuracy of fit of each measuring point in group 3 (CEREC SW 4.2, $40 \mu \mathrm{m}$ ). Uppermost point and lowermost point indicate the highest and lowest values of results. The top of box and bottom of box indicate the $75 \%$ and $25 \%$ values of results. The midline in the box means the average of the results 


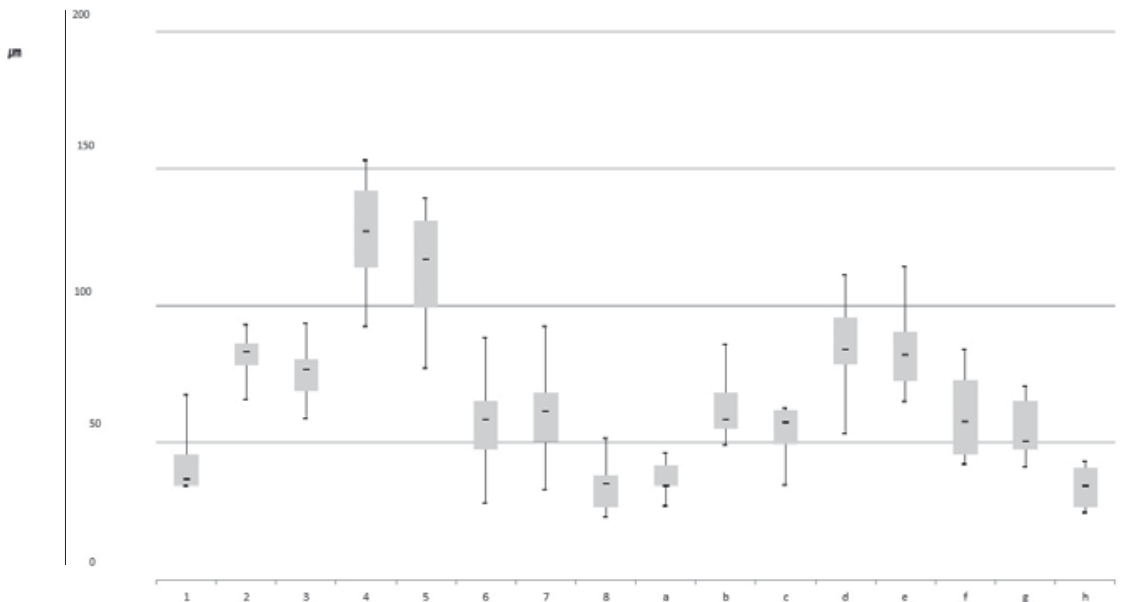

Figure 6- Accuracy of fit of each measuring point in group 4 (CEREC SW 4.2, $80 \mu \mathrm{m}$ ). Uppermost point and lowermost point indicate the highest and lowest values of results. The top of box and bottom of box indicate the $75 \%$ and $25 \%$ values of results. The midline in the box means the average of the results

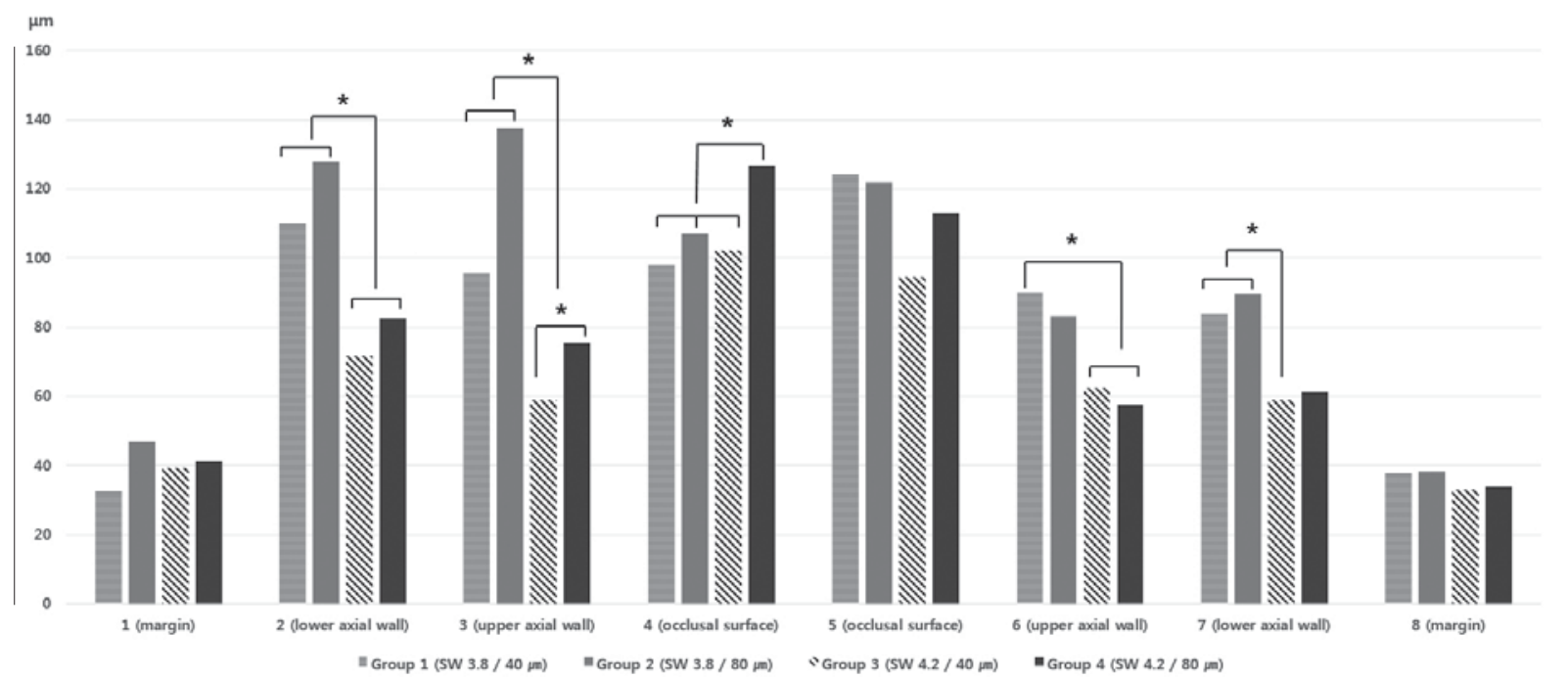

Figure 7- Mean internal fit $(\mu \mathrm{m})$ of each measuring points on buccolingually sectioned surface. *indicates statistically significant differences

Although we expected the larger spacer parameter setting would have caused a larger gap between crown and tooth, the use of $40 \mu \mathrm{m}$ as the spacer parameter setting in the version 3.8 of the software produced a larger gap when compared to the setting of the spacer at $80 \mu \mathrm{m}$ for the six measuring points, including 5 (occlusal surface), 6 (upper axial wall), a (margin), b (lower axial wall), c (upper axial wall), and h (margin). On the contrary, for the version 4.2 of the software, one measuring point (i.e., point 6 of upper axial wall) showed a smaller gap with a $40 \mu \mathrm{m}$ spacer setting when compared with the group selecting $80 \mu \mathrm{m}$, while the group selecting $80 \mu \mathrm{m}$ in the version 4.2 of the software showed the least variations among the results.

\section{SCUSSION}

The process of dental restorations using CAD/ CAM technology involves data acquisition, data processing, and manufacturing. The aim of this study was to evaluate the effect of data processing on the adaptation of crown restorations. Variables such as different versions of software and space parameters were analyzed in the four groups of crown impressions, and the fit of the crown was measured using the replica technique. As the results showed, the crowns designed using the version 4.2 of the software produced a better fit than those designed using the version 3.8 of the software, particularly in the axial wall. The spacer parameter was more accurately represented in the version 4.2 of the software than in the version 3.8. In addition, the use of the version 4.2 of the software combined 


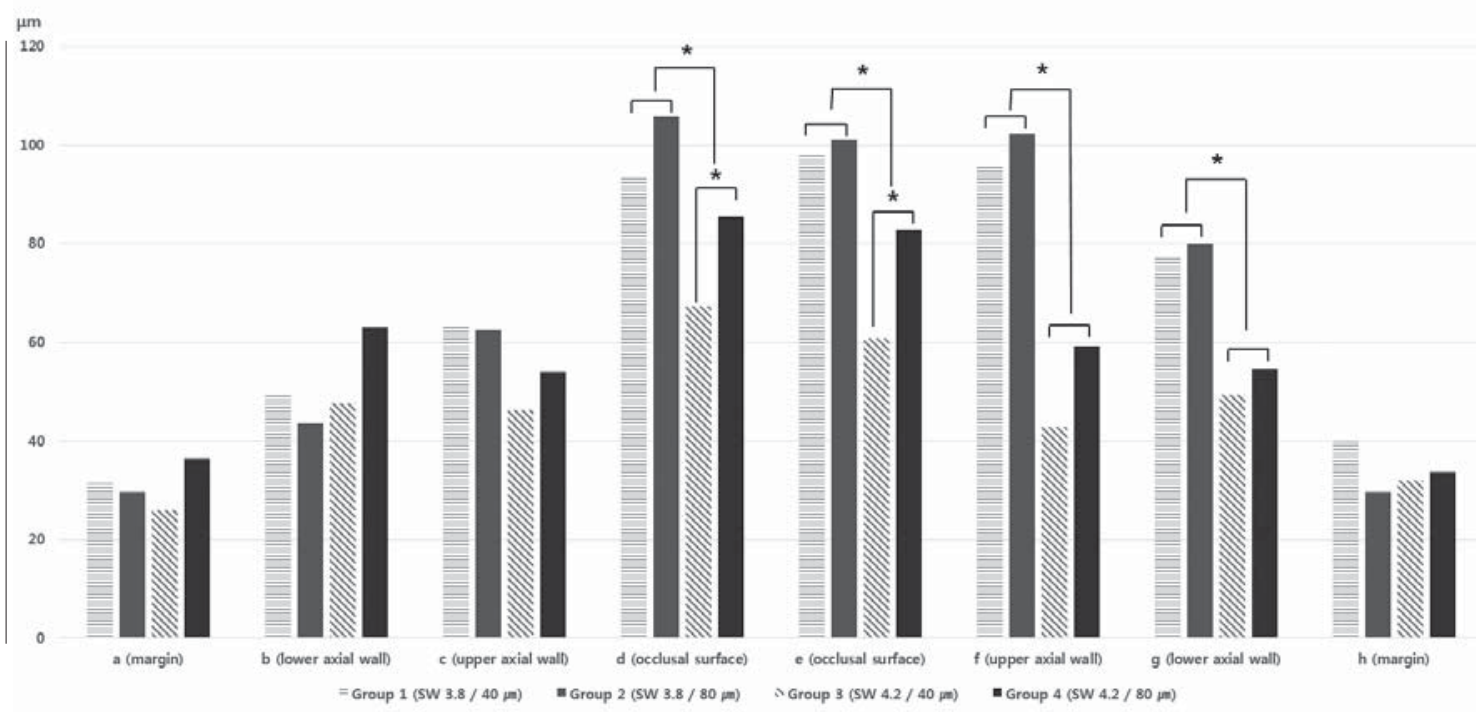

Figure 8- Mean internal fit $(\mu \mathrm{m})$ of each measuring points on mesiodistally sectioned surface. *indicates statistically significant differences

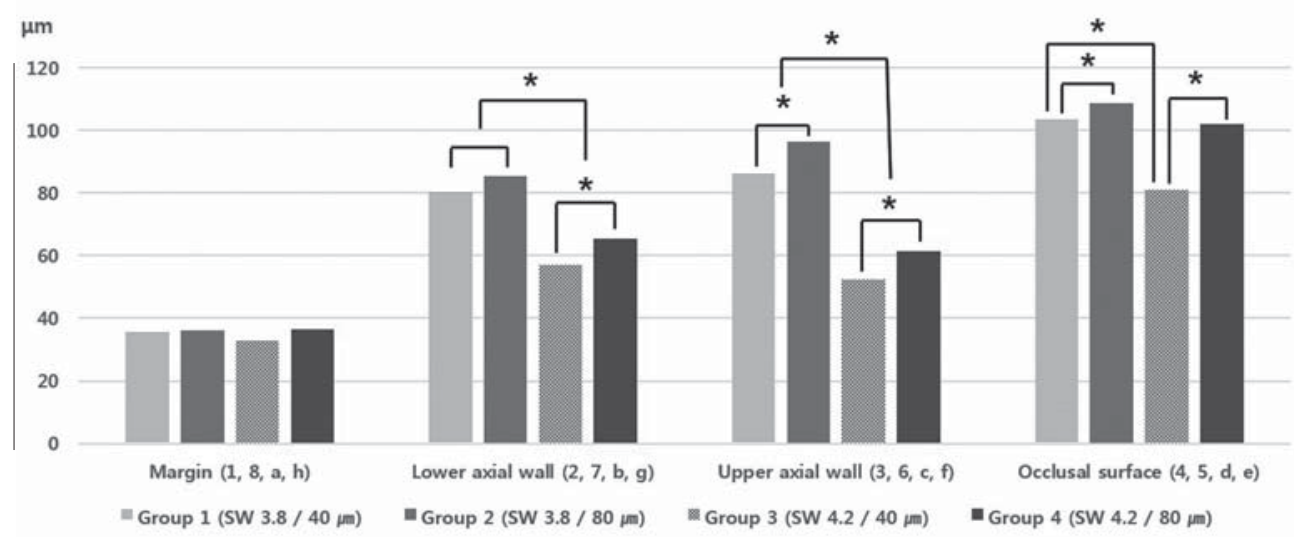

Figure 9- The results of each average values of measuring points categorized as margin (1, 8, a, h), lower axial wall (2, 7, b, g), upper axial wall $(3,6, c, f)$ and occlusal suface $(4,5, d, e)$. *indicates statistically significant differences

Table 1- Two-way ANOVA analysis showing that software version and spacer parameter significantly affected the fit of the crowns $(p<.05)$

\begin{tabular}{cc}
\hline Independent variable & Significance \\
\hline Software Version & $\mathrm{p}<0.05$ \\
Space Parameter & $\mathrm{p}<0.05$ \\
\hline
\end{tabular}

with the spacer parameter set at $80 \mu \mathrm{m}$ showed the least variation. On the other hand, the outer margin was not affected by the variables.

Such parameters indicate the setting factors to determine particular features of a restoration in CAD/CAM system. The cement space, the contact strength, the occlusion strength, and the minimum thickness of a restoration can be easily changed as providing different parameter in the CAD/CAM system. Space parameter can be set from -100 to $100 \mu \mathrm{m}$ in the version 3.8, and from 0 to $100 \mu \mathrm{m}$ in the version 4.2. Among the overlapped space parameter (from 0 to $100 \mu \mathrm{m}$ ), 40 and $80 \mu \mathrm{m}$ were used in this study. Forty $\mu \mathrm{m}$ is commonly used as space parameter because resin cements range from 20 to $35 \mu \mathrm{m}$ concerning the thickness of their film; the $80 \mu \mathrm{m}$ is the double value of $40 \mu \mathrm{m}$ to evaluate the effect of space parameter.

To fabricate well-fitting dental crowns using CAD/CAM systems in the clinic, the optimal combination involving the intraoral scanner, the software version, and the milling machine is important. Although many studies have compared the fit of crown restorations fabricated with different intraoral scanners ${ }^{16,20}$ and milling machines ${ }^{19}$, there have been few studies evaluating the effect of different versions of the software. The results of 
this study showed the fit of a restoration could be affected by the software version and the spacer parameter setting, even when the same scanner and milling machine were used. Compared to the version 3.8 of the CAD/CAM software, the version 4.2 of this software can be recommended for the fabrication of well-fitting crown restorations, and for the appropriate regulation of the spacer parameter. Even though the $80-\mu \mathrm{m}$ spacer setting produced a larger gap, this setting could be recommended for the version 4.2 of the CAD/CAM software because it showed a good repeatability.

Adequate marginal gaps and internal fits are decisive factors for the clinical longevity of crown restorations ${ }^{10}$. A large marginal gap can cause discoloration, disintegration of cement, plaque retention, and gingival inflammation ${ }^{1,3}$. The recommended marginal gap for the prevention of the above mentioned complications ${ }^{7,8}$ is below 100 $\mu \mathrm{m}$. The results obtained in this study showed a clinically acceptable marginal fit could be achieved regardless of the software version and of the spacer parameter settings, with an average gap of $35 \mu \mathrm{m}$. A larger internal gap could produce restorative fractures and postoperative sensitivity. The results of this study demonstrated the version 3.8 of the software and the spacer parameter set at $40 \mu \mathrm{m}$ produced a relatively larger internal gap when compared with the version 4.2 of the software and with the spacer parameter set at $80 \mu \mathrm{m}$. The use of a sufficient amount of cement with harder mechanical properties is recommended in these cases to avoid the complications caused by large internal gaps.

Although zirconia is one of the most popular materials used in the fabrication of crowns by utilizing the CAD/CAM system, the additional process of sintering may introduce variability among crowns. For the accurate evaluation of the effect of the version of the software and of the spacer parameter settings, Lava ${ }^{\mathrm{TM}}$ Ultimate Restorative, a resin of nano ceramic material that does not require the sintering process was selected as the restoration material in this study ${ }^{11}$. Compared with previous studies ${ }^{14,19}$, the smaller marginal and internal gaps reported in this study could be due to the use of a different restoration material. The marginal adaptation was evaluated using the replica technique. Although measurements using a digital 3D scanner are precise, convenient, and easily visualized, the replica technique is the appropriate measurement tool for the accurate assessment of multiple points in the internal surface of restorations fabricated using the CAD/CAM system ${ }^{22}$.

The generally recognized improvement introduced by the version 4.2 of the software compared with the version 3.8 is an increased convenience for the use of the CEREC CAD/CAM system. The version 4.2 .5 is already available these days, being a supplementary version of the 4.2 and it does not seem to have big functional differences with the version 4.2. The results of this study showed that a smaller internal gap could be obtained using the version 4.2 of the software, particularly at the axial wall, despite the fact the marginal gap was almost the same. The improvement of the adaptation obtained with the version 4.2 of the software could be in part due to differences in the pre-set space, basically providing space regardless of the parameter setting at the internal part between software versions. It has been shown that a greater internal space resulted in less marginal gap leading to less internal premature contact ${ }^{4}$; a greater internal space might be necessary for achieving an adequate marginal gap in crown restorations, taking into account the accuracy and reproducibility of intraoral scanners and milling machines that are currently used with the version 3.8 of the software. Another possible explanation could be the improvement in resolution of the version 4.2 of the software during the processing of the acquired data through the intraoral scanner.

The application of the CAD/CAM technology in dentistry have been producing improvement not only in dental clinics but also in dental laboratories ${ }^{6}$. Many studies are using the AD/CAM technology to compare it with conventional methods or to manage it as a tool to measure specimens. Our results suggest that, to achieve accurate comparisons across studies, all reports should specify the software version and the space parameter settings used (additional studies of reference on the effect of various software and parameters will be necessary).

\section{CONCLUSI ONS}

The fit of a crown restoration can be affected by the specific CAD/CAM software version and by the parameter settings selected, even if the same scanner and milling machine were used. In comparison with the version 3.8 of the CAD/ CAM software, the version 4.2 of this software can be recommended for the fabrication of wellfitting crown restorations, and for the appropriate regulation of the spacer parameter. Even though the $80-\mu \mathrm{m}$ spacer setting produced a larger gap, this setting can be recommended for the version 4.2 of the CAD/CAM software because it has shown a good repeatability.

\section{ACKNOWLEDGEMENTS}

No author has financial support or financial interest in any of the materials or methods mentioned. 


\section{REFERENCES}

1- Addi S, Hedayati-Khams A, Poya A, Sjögren G. Interface gap size of manually and CAD/CAM-manufactured ceramic inlays/ onlays in vitro. J Dent. 2002;30(1):53-8.

2- Albert FE, El-Mowafy OM. Marginal adaptation and microleakage of Procera AllCeram crowns with four cements. Int J Prosthodont. 2004;17(5):529-35.

3- Baig MR, Tan KB, Nicholls JI. Evaluation of the marginal fit of a zirconia ceramic computer-aided machined (CAM) crown system. J Prosthet Dent. 2010;104(4):216-27.

4- Bindl A, Mörmann WH. Fit of all-ceramic posterior fixed partial denture frameworks in vitro. Int J Periodontics Restorative Dent. 2007;27(6):567-75.

5- Ender A, Mehl A. Accuracy of complete-arch dental impressions: a new method of measuring trueness and precision. J Prosthet Dent. 2013;109(2):121-8.

6- Fasbinder DJ. Clinical performance of chairside CAD/CAM restorations. J Am Dent Assoc. 2006;137(Suppl):22S-31S.

7- Gassino G, Barone Monfrin S, Scanu M, Spina G, Preti G. Marginal adaptation of fixed prosthodontics: a new in vitro 360-degree external examination procedure. Int J Prosthodont. 2004;17(2):218-23.

8- Groten M, Girthofer S, Pröbster L. Marginal fit consistency of copy-milled all-ceramic crowns during fabrication by light and scanning electron microscopic analysis in vitro. J Oral Rehabil. 1997;24(12):871-81

9- Henkel GL. A comparison of fixed prostheses generated from conventional vs digitally scanned dental impressions. Compend Contin Educ Dent. 2007;28(8):422-4, 426-8, 430-1.

10- Keshvad A, Hooshmand T, Asefzadeh F, Khalilinejad F, Alihemmati M, Van Noort R. Marginal gap, internal fit, and fracture load of leucite-reinforced ceramic inlays fabricated by CEREC inLab and hot-pressed techniques. J Prosthodont. 2011;20(7):535-40. 11- Koller M, Arnetzl GV, Holly L, Arnetzl G. Lava ultimate resin nano ceramic for CAD/CAM: customization case study. Int J Comput Dent. 2012;15(2):159-64.
12- Laurent M, Scheer P, Dejou J, Laborde G. Clinical evaluation of the marginal fit of cast crowns - validation of the silicone replica method. J Oral Rehabil. 2008;35(2):116-22.

13- Li RW, Chow TW, Matinlinna JP. Ceramic dental biomaterials and CAD/CAM technology: state of the art. J Prosthodont Res. 2014;58(4):208-16.

14- Martins LM, Lorenzoni FC, Melo AO, Silva LM, Oliveira JL, Oliveira PC, et al. Internal fit of two all-ceramic systems and metalceramic crowns. J Appl Oral Sci. 2012;20(2):235-40.

15- Molin M, Karlsson S. The fit of gold inlays and three ceramic inlay systems. A clinical and in vitro study. Acta Odontol Scand. 1993;51(4):201-6.

16- Nedelcu RG, Persson AS. Scanning accuracy and precision in 4 intraoral scanners: an in vitro comparison based on 3-dimensional analysis. J Prosthet Dent. 2014;112(6):1461-71.

17- Ng J, Ruse D, Wyatt C. A comparison of the marginal fit of crowns fabricated with digital and conventional methods. J Prosthet Dent. 2014;112(3):555-60.

18- Otto T, De Nisco S. Computer-manufactured, direct ceramic restorations: a prospective, clinical 10 -year study of Cerec CAD-CAM inlays and onlays. Schweiz Monatsschr Zahnmed. 2003;113(2):156-69.

19- Patzelt SB, Bishti S, Stampf S, Att W. Accuracy of computeraided design/computer-aided manufacturing-generated dental casts based on intraoral scanner data. J Am Dent Assoc. 2014;145(11):1133-40.

20- Patzelt SB, Emmanouilidi A, Stampf S, Strub JR, Att W. Accuracy of full-arch scans using intraoral scanners. Clin Oral Investig. 2014;18(6):1687-94.

21- Quintas AF, Oliveira F, Bottino MA. Vertical marginal discrepancy of ceramic copings with different ceramic materials, finish lines, and luting agents: an in vitro evaluation. J Prosthet Dent. 2004;92(3):250-7.

22- Rahme HY, Tehini GE, Adib SM, Ardo AS, Rifai KT. In vitro evaluation of the "replica technique" in the measurement of the fit of Procera crowns. J Contemp Dent Pract. 2008;9(2):25-32. 